\author{
ks. Andrzej Draguła ${ }^{1}$ \\ 0000-0002-3287-3119 \\ Uniwersytet Szczeciński
}

\title{
Fides ex visu. O medialnych wizualizacjach wiary
}

Na samym wstępie należy poczynić istotne zastrzeżenie metodologiczne: artykuł nie podejmuje problemu treściowej analizy mediów, także w ich aspekcie wizualnym. Zagadnienie to domaga się zresztą szczegółowych badań medioznawczych. Chodzi raczej o to, by pójść drogą wyznaczoną przez Marshalla McLuhana i skupić się na samym medium, na wizualności jako języku przekazu mediów, zwłaszcza mediów elektronicznych i na ich korelacji z wiarą. McLuhan stawiał pytanie, co media robią z ludźmi. Jak wiemy, zgodnie z jego koncepcją determinizmu technologicznego, samo medium jest przesłaniem (the medium is the message) i działa niezależnie od przekazywanej treści. Można tutaj zauważyć dużą zbieżność myśli McLuhana z koncepcjami współczesnych myślicieli z obszaru antropologii obrazu i historii sztuki, jak William John Thomas Mitchell, Hans Belting czy David Freedberg, którzy mówią - rzecz ogólnie

1 Ks. Andrzej Draguła - ksiądz diecezji zielonogórsko-gorzowskiej, dr hab. teologii, prof. Uniwersytetu Szczecińskiego, kierownik Katedry Teologii Praktycznej na WTUS. Publicysta, członek Rady Naukowej Laboratorium „Więzi” i redakcji „Więzi”. Uprawia teologię w perspektywie kulturowej. E-mail: andrzej.dragula@usz.edu.pl. 
ujmując - o „działaniu obrazów”2. Obraz jest nie tylko do oglądania, obraz czegoś chce, czegoś się domaga, chce coś osiągnąć.

Interesujące nas pytanie dotyka zagadnienia, które sformułował Belting, dzieląc historię wizualności na dwie epoki: epokę obrazu, który stał w centrum kultu oraz epokę sztuki, gdy obraz stał się (prawie) wyłącznie przedmiotem estetycznym. Piękno teologiczne oparte na obiektywnych kanonach zostało zastąpione pięknem estetycznym związanym ze zmysłowymi wrażeniami. O tej pierwszej epoce Belting pisał: „W końcu należało nie tylko oglądać obrazy, ale dawać im wiarę"3. Obraz - w swej prymarnej roli - nie był niegdyś po to, by się podobał, ale po to, by objawiał, przypominał czy wskazywał inną, duchową, nadprzyrodzoną rzeczywistość i w tym znaczeniu rzeczywiście należało mu „dawać wiarę”. Był więc przedmiotem wiary, a w konsekwencji - przedmiotem czci i kultu. Zwrot renesansowy sprawił, że - jak zauważa Joanna Winnicka-Gburek „Z nowej, artystycznej perspektywy zaczęto patrzeć na obrazy będące kiedyś przedmiotem czci" ${ }^{4}$, a dzieła sakralne ustąpiły miejsca sztuce o tematyce religijnej. Pytanie, które należałoby postawić, brzmi: czy media wizualne zdolne są wskrzesić obraz w jego pierwotnym, kultycznym znaczeniu? Można czy należy „dawać wiarę” współczesnej, elektronicznej wizualności? od porządku semantycznego bardziej interesował nas będzie więc porządek semiotyczny.

\section{Obraz i pamięć}

Jednym z zagadnień podejmowanych w encyklice Lumen fidei papieża Franciszka jest kwestia związku wiary z widzeniem. Chociaż ojciec święty udowadnia, że w Ewangelii według św. Jana starotestamentalna opozycja

2 H. Belting, Obraz i kult. Historia obrazu przed epoką sztuki, tłum. T. Zatorski, Gdańsk 2004; D. Freedberg, Potęga wizerunków. Studia z historii i teorii oddziaływania, tłum. E. Klekot, Kraków 2005; W. J. T. Mitchell, Czego chca obrazy. Pragnienia przedstawien, życie i miłości obrazów, tłum. Ł. Zaremba, Warszawa 2013.

3 H. Belting, Obraz i kult..., dz. cyt., s. 20.

4 J. Winnicka-Gburek, Krytyka-etyka-sacrum. W kierunku aksjologicznej krytyki artystycznej, Gdańsk 2015, s. 37. 
między widzeniem a słyszeniem zostaje ostatecznie pokonana, to jednak trudno się zupełnie zgodzić z tezą, że opozycja między tymi dwoma rodzajami poznania została na zawsze zniesiona oraz że te dwa sposoby poznania, także poznania teologicznego, nie są przyporządkowane dwóm różnym tradycjom kulturowym: semickiej opartej przede wszystkim na słyszeniu (choć - jak zauważa papież - „słuchanie słowa Bożego łączy się z pragnieniem oglądania oblicza Boga" ${ }^{5}$, z pragnieniem, ale nie z samym oglądaniem) oraz helleńskiej, dla której właściwa jest dominacja poznania wizualnego, wszak to właśnie Grecy przychodzą z prośbą do Filipa: „Chcemy widzieć Jezusa” (J 12, 21). „W ten sposób stał się możliwy dialog z kulturą helleńską" - twierdzi papież Franciszek ${ }^{6}$. I ten dialog między genetycznie semicką przecież Ewangelią a helleńskim kształtem wiary w nią wciąż trwa.

Teologia wizualności narodziła się najpierw w kręgu bizantyńskim. Święty Jan z Damaszku († ok. 749), czyli św. Jan Damasceński, opisywał związek między widzeniem a wiarą, włączając między nimi kategorię pamięci (memoria), która to kategoria zdominowała średniowieczną teologię obrazu. Uważał on, że ważne wydarzenia zbawcze przedstawia się na obrazach „dla łatwiejszego pamiętania o nich, gdyż obraz jest przypomnieniem dla pamięci”, podobnie jak książka w odniesieniu do słów. „Często się zdarza - pisał św. Jan Damasceński - że chociaż w danej chwili nie myślimy o Męce Pańskiej, to na widok obrazu przedstawiającego ukrzyżowanego Chrystusa natychmiast wspominamy Zbawczą Mękę i pokornie adorujemy - nie materię obrazu, lecz to, co on przedstawia"7. Pamięć jest nieodłączna z obrazem, z tym, co przypomniane, wyobrażone na nowo, postawione „przed oczyma duszy”. Orędzie usłyszane wcześniej, zostaje skojarzone z obrazem, które je ilustruje, a potem funkcjonuje jako „wyzwalacz” zasłyszanej treści. Według Alfreda Wierzbickiego, zarówno słowo, jak i obraz pełnią ,jedynie rolę narzędzia dającego realne uczest-

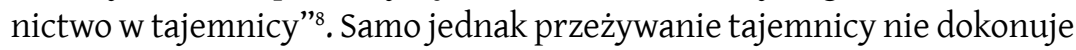

\footnotetext{
Franciszek, Encyklika Lumen fidei, Wrocław 2013, nr 29, s. 37.

Franciszek, Encyklika Lumen fidei, dz. cyt., nr 29, s. 38.

7 Jan Damasceński, Wykład wiary prawdziwej, tłum. B. Wojkowski, Warszawa 1969, s. 233.

8 A. Wierzbicki, Tajemnica telewizji, w: O Panu Bogu w telewizji, red. L. Dyczewski, Częstochowa 1996, s. 116-117.
} 
się „w obrazie” czy „w słowie”, lecz „w pamięci”. To „pamięć jest tym wymiarem życia duchowego, który aktualizuje wydarzenie-tajemnicę i karmi się obrazami"'. W momencie oglądania obrazu przypomina się to, co w pamięci łączy się z oglądanym właśnie wizerunkiem. Aktualna wizja cielesna (ex visu) łączy się z wizją duchową, która zrodziła się ze słuchania słowa Bożego (ex auditu) i trwa w pamięci. Akt oglądania jest wejściem tych dwóch wizji w relację ze sobą. Powołując się na lubelskiego filozofa, Arkadiusza Guta, Witold Kawecki pisze, że „nie rozstrzygniemy dylematu z zakresu filozofii umysłu, mianowicie czy nasze myślenie ma charakter werbalny czy też figuratywny (obrazowy)"10. Teologowie przełomu starożytności i średniowiecza nie mieli jednak wątpliwości, iż pamięć jest ze swej natury obrazowa. Wprowadzenie kategorii pamięci do zachodniej teologii modlitwy zawdzięczamy Amalariuszowi z Metzu (ok. 755 - ok. 850), który w swoim wykładzie Mszy św. (De ecclesiasticis officiis, „Święte obrzędy Kościoła”), używa wyrażeń: in memoriam reducere, ad memoriam reducere, czyli „przywoływać na pamięć”, „przypominać”. Według niektórych komentatorów memoria rozumiana była przez niego w znaczeniu obrazu, co może znajdować swoje wytłumaczenie w kontakcie Amalariusza z teologią wschodnią, do czego doszło w trakcie jego podróży do Bizancjum ${ }^{11}$.

Także współcześni myśliciele skłaniają się do przekonania, że nośnikiem pamięci jest obraz. Susan Sontag w Widoku cudzego cierpienia pisze: „Pamięć działa na zasadzie stopklatki; jej podstawową jednostką jest pojedynczy obraz"12. Z kolei David Morgan twierdzi, że pamięć działa na sposób ikoniczny w tym znaczeniu, że próbuje odzyskać i zatrzymywać przeszłość, by na nowo przedstawić to, co jest przeszłością

9 A. Wierzbicki, Tajemnica telewizji, dz. cyt., s. 117; por. H. Belting, Obraz i kult, dz. cyt., s. 16.

10 W. Kawecki, Zobaczyć wiarę. Studium obrazu postrzeganego jako komunikacja wiary z perspektywy teologii kultury i teologii mediów, Kraków 2013, s. 79; zob. A. Gut, O relacji między myśla a językiem: studium krytyczne stanowisk utożsamiających myśl z językiem, Lublin 2009.

11 Zob. R. Niparko, Amalary z Metzu, w: Encyklopedia katolicka, t. 1, red. E. Gigilewicz, Lublin 1995, kol. 399.

12 S. Sontag, Widok cudzego cierpienia, Kraków 2010, s. 30. 
i aby - w jakimś ograniczonym sensie - mogło to wydarzyć się na nowo ${ }^{13}$. „Akt przypominania - pisze Morgan - ma charakter magiczny, gdyż powtarza przeszłość w umysłowej wyobraźni, a także w uczuciach, czasie, miejscu i formie materialnej w ten sposób, że działa jako rodzaj śladu zmysłowego"14.

Ten zmysłowy ślad - jak zauważa kard. Christoph Schönborn - ma ambiwalentny charakter. Raz zobaczone obrazy

wyciskają [...] znamię na naszych wyobrażeniach i myślach, odkładają się warstwami w naszej pamięci - zawsze gotowe obudzić się w nas, niezależnie od tego, czy chcemy czy nie, wynurzają się z przeszłości, by działać na teraźniejszośćc ${ }^{15}$.

Wyobraźnia retrospektywna siłą rzeczy karmi się jedynie tymi obrazami, które zostały utrwalone w pamięci, dlatego tak ważna jest wstrzemięźliwość wzroku. To właśnie od obrazów przechowywanych w naszej pamięci zależy nasze myślenie i nasz język. Dlatego Schönborn pisze: „Niewykluczone, że ascetyczne podejście do obrazów stanowi dzisiaj jedną z najważniejszych form ascezy"16. Raz zobaczone obrazy zapadają w pamięć. Z czasem ulegają zatarciu, a nawet można je zapomnieć, nie da się ich jednak usunąć z pamięci siłą woli, postanowić ich nie pamiętać. Dotyczy to wszystkich obrazów, zarówno tych pięknych i budzących pozytywne emocje u odbiorcy, jak również tych, które przypominają o doświadczeniach negatywnych. Każdy człowiek jest więc bezpośrednio odpowiedzialny za to, co widzi i co pozostaje w jego wizualnej pamięci. Schönborn pisze, iż

możliwe, że tendencja do surowych form religijności zrodziła się z intuicji podpowiadającej nam konieczność wyciszania naszej percepcji, tak by natłok obrazów nie przesłaniał nam rzeczywistości ${ }^{17}$.

13 D. Morgan, Visual Piety. A History and Theory of Popular Religious Images, Berkeley-Los Angeles-London 1998, s. 192-195.

14 D. Morgan, Visual Piety..., dz. cyt., s. 195.

15 Ch. Schönborn, Człowiek i Chrystus na obraz Boga, tłum. W. Szymona, Poznań 2008, s. 96.

16 Ch. Schönborn, Człowiek i Chrystus na obraz Boga, dz. cyt., s. 97.

17 Ch. Schönborn, Człowiek i Chrystus na obraz Boga, dz. cyt., s. 97. 


\section{Ekran jako obraz}

Należy sobie teraz odpowiedzieć na pytanie, na ile to, co zostało dotychczas powiedziane w odniesieniu do tradycyjnego obrazu, który ujawnia się jako picture, można zastosować wobec obrazu, który ujawnia się jako ekran elektroniczny bądź na ekranie. Obraz - nazwijmy go roboczo - medialny, który widzimy na ekranie telewizora, komputera, smartfona czy tableta, różni się bowiem co do natury od obrazu tradycyjnego, tzn. namalowanego, narysowanego czy wyrzeźbionego. Cóż to jest ekran? „Ekran - pisze Antoni Porczak - najogólniej można zdefiniować jako wydzielony fragment przestrzeni o zagęszczonej zawartości informacyjnej; jest on bytem medialnym, który sprowadza do przestrzeni naszego bytowania świat zewnętrzny"18. Podobnie ekran definiuje Lev Manovich, według którego ekran wyznacza „istnienie innej, wirtualnej przestrzeni, innego trójwymiarowego świata otoczonego ramą i umieszczonego w naszej, zwykłej przestrzeni"19. Między tradycyjnym obrazem a ekranem istnieje istotna różnica percepcyjna. Tradycyjny obraz to przestrzeń poza odbiorcą, coś, w czym mnie nie ma. Obraz ekranowy opiera się na iluzji obecności w przestrzeni ujawniającej się na ekranie. Jak pisze Tadeusz Miczka, jednym ze współczesnych przesunięć komunikacyjnych jest „zastępowani percepcji różnymi formami «przebywania» człowieka w obrazie audiowizualnym”20. 0 ile ,istota tradycyjnej percepcji zasadza się na odczuwaniu dystansu do obrazu i traktowania go jako świata całkowicie fikcyjnego”, to „inkluzja ekranowa” polega na tym, iż „wrażenie występujące podczas oglądana obrazów staje się wrażeniem występującym podczas przebywania w miejscu"21. Ekran o wiele bardziej niż wszystkie wcześniejsze formy obrazu daje patrzącemu poczucie uczestnictwa w rzeczywistości pokazanej na obrazie.

18 A. Porczak, Ekran - pole transakcji, w: Wiek ekranów. Przestrzenie kultury widzenia, red. A. Gwóźdź, P. Zawojski, Kraków 2002, s. 45.

19 L. Manovich, Ku archeologii ekranu komputerowego, w: Widzieć, myśleć, być. Technologie mediów, red. A. Gwóźdź, Kraków 2001, s. 168.

20 T. Miczka, O zmianie zachowań komunikacyjnych. Konsumenci w nowych sytuacjach audiowizualnych, Katowice 2002, s. 127.

${ }_{21}^{21}$ T. Miczka, O zmianie zachowań komunikacyjnych..., dz. cyt., s. 127. 
Nie można jednak zapomnieć, iż obraz elektroniczny ma zupełnie odmienny status od tradycyjnie rozumianego obrazu. Słusznie zauważa Witold Kawecki, że

telewizja stała się szczególną formą z jednej strony oglądu świata, a z drugiej wytwarzania świata wirtualnego, który w miejsce audiowizualnych przedstawień produkuje rzeczywistość w formie obrazów ${ }^{22}$.

Ekran nie jest ani przed-stawieniem, ani re-prezentacją tego, co istnieje poza nim i wcześniej od niego, ale ma pretensje do samoistności. W ekranie elektronicznym dochodzi do substytucji rzeczywistości przez uniwersum znakowe mediów, które staje się realniejsze od samej rzeczywistości. Obraz elektroniczny nie ma żadnej realności poza sobą, faktycznie bowiem nie jest reprezentacją czegokolwiek, lecz jedyne symulacją czegoś nowego i utożsamia się tylko z samym sobą, nie odwołując się do żadnego oryginału: ani odwiecznego prototypu - jak to było w ikonie, ani do rzeczy realnej - jak to było w obrazie mimetycznym, naśladowczym, który znamy od renesansu. W ten sposób ekran wpisuje się w Baudrillardowską koncepcję symulakrów i symulacji, zacierając tym samym granicę między prawdziwym a fałszywym, rzeczywistością a wyobraźnią, realnością a hiperrealnością. W rozumieniu Jeana Baudrillarda bowiem obraz elektroniczny nie przedstawia nam już rzeczywistości, gdyż sam stał się rzeczywistością ${ }^{23}$. Ekran telewizyjny nie ukazuje ani obrazu, ani jego reprezentacji, ale „raczej pozory reprezentacji jako takiej”, „pewien rodzaj wizji" - jak to określa sam nazwa tego medium, czyli telewizji ${ }^{24}$.

Jeszcze dalej idzie Jean-Luc Marion, według którego obraz elektroniczny to „antyświat w świecie” bądź „przeciw-świat”, gdyż jest wytwarzany „w czasie nieprzerwanym i przestrzeni nieograniczonej, które naśladują czas i przestrzeń świata, nie przynależąc jednak do świata”25.

22 W. Kawecki, Zobaczyć wiarę..., dz. cyt., s. 61.

23 Zob. K. Loska, Dziedzictwo McLuhana - między nowoczesnością a ponowoczesnością, Kraków 2001, s. 117.

${ }^{24}$ Zob. S. Weber, Telewizja: odbiornik i ekran, w: Widzieć, myśleć, być. Technologie mediów, red. A. Gwóźdź, Kraków 2001, s. 388-389.

25 Zob. J.-L. Marion, Ślepy w Siloe, czyli odniesienie obrazu do oryginału, „Communio” (wyd. pol.) 2 (1990), s. 15-16. 
Obraz na ekranie - kontynuuje uczony - jako forma bez materii, ma jedynie realność widmową, niematerialną, a „fikcja i fałszerstwo należą do normalnego porządku obrazu zjawiającego się na ekranie telewizyjnym"26. Kawecki dodaje:

Za sprawą Waltera Cronitke'a [amerykański dziennikarz] utarło się przekonanie, że „obraz nie kłamie”, gdyż jest tym, czym jest i mówi za siebie. Tymczasem wiemy, że obraz może kłamać, nie sam z siebie, ale wtedy, kiedy jest świadomie albo nawet nieświadomie użyty w pewnym kontekście i w taki sposób, że nie oddaje rzeczywistości, którą przedstawia. Dotyczy to w szczególności obrazu telewizyjnego, fotomontażu, będącego nierzadko złudą, kłamstwem, manipulacją ${ }^{27}$.

Ikona odtwarza odwieczny prototyp, obraz mimetyczny - realny świat, ekran - inaczej niż jego poprzednicy - nie jest ani ikoniczną reprezentacją prototypu, ani analogonem świata. Będąc częściową reprodukcją rzeczywistości i jednocześnie rekonstrukcją mającą za punkt wyjścia tę rzeczywistość, ekran ma naturę hybrydową. Podczas komponowania ekranu telewizyjnego realizator wybiera jakąś część rzeczywistości i wychodząc z tego wyselekcjonowanego fragmentu, w arbitralny sposób przekazuje założoną przez siebie treść. Odbiorca nie widzi więc rzeczywistości, lecz jedynie obraz rzeczywistości w kształcie proponowanym przez tego, kto go pokazuje. Ekran nie jest więc imitacją rzeczywistości, ale arbitralną narracją o rzeczywistości. Jest wizją czyjejś wizji. Jak podkreśla Samuel Weber,

logika i ontologia, które rządzą tradycyjnymi relacjami mimesis, reprodukcji i reprezentacji, zostają unieważnione. To, co widać, na ekranie, nie jest wcześniej przygotowanym dziełem, ale quasi-symultaniczną inną wizją, reprodukowaną tu i teraz ${ }^{28}$.

W ten sposób obraz elektroniczny przestaje być odwzorowaniem rzeczywistości, a staje się miejscem kreacji hiperrzeczywistości, nowej rzeczywistości, rzeczywistości równoległej. W wyniku mediatyzacji rzeczywistości, czyli nasycenia jej własnymi obrazami, dochodzi do takiego

26 J.-L. Marion, Ślepy w Siloe, czyli odniesienie obrazu do oryginału, dz. cyt., s. 15.

27 W. Kawecki, Zobaczyć wiarę..., dz. cyt., s. 62.

28 S. Weber, Telewizja: odbiornik i ekran, dz. cyt., s. 391-392. 
przekształcenia rzeczywistości realnej, by dopasować się do medialnego wyobrażenia na jej temat. Inaczej mówiąc, to nie media (telewizja) starają się odwzorować rzeczywistość obiektywną, ale to rzeczywistość obiektywnie istniejąca stara się dopasować do wzoru, jakim dla niej staje się hiperrealna rzeczywistość medialna, ekranowa. W konsekwencji prawdziwe staje się nie to, co rzeczywiście jest, ale to, jak to zostało pokazane w mediach. Rzeczywistość próbuje się do tego ideału dopasować. Rzeczywistość ekranowa staje się „wzorcotwórcza” dla rzeczywistości realnej, obiektywnej, która przeradza się w jej kontynuację. Następuje odwrócenie continuum między światem a światem ekranowym. W konsekwencji realna rzeczywistość istnieje jedynie w formie medialnych reprezentacji. „Hiperrealność - pisze Agnieszka Ogonowska - powstaje w wyniku ciągłego zastąpienia rzeczywistości przez jej znaki, które niwelują granicę między prawdą a fałszem oraz między światem «rzeczywistości» a światem fikcji [...]. Świat zastąpiony całkowicie przez swój obraz, musi ponownie się urzeczywistnić"29.

Hiperrealny świat wytworzony przez ekrany mediów i ich odbiorców jest prawdziwszy i piękniejszy. Dlatego „widz patrzy dla samej radości patrzenia” - jak pisze Jean-Luc Marion ${ }^{30}$. „Obrazy telewizyjne, będące w nieustannym ruchu, mają cechę zmysłowej rzeczywistości. Z tego względu wywierają większe wrażenie niż inne środki wyrazu" - zauważa Kawecki ${ }^{31}$. Do tego dochodzi - raz jeszcze Marion -

radość płynąca z oglądania, widzenia wszystkiego, a zwłaszcza tego, czego nie powinienem oglądać, wreszcie radość z tego, że widzę, a nie jestem widziany - krótko mówiąc: panowanie, dzięki wzrokowi, nad tym, co nie moje, bez wystawiania się na widok innych ${ }^{32}$.

Marion określa to mianem libido videndi - pożądanie oglądania. Radość, przyjemność oglądania stają się jedynym kryterium tworzenia

29 A. Ogonowska, Symulakrum, „Nowa Polszczyzna” 1 (2006), s. 30; por. J. Baudrillard, Porządek symulakrów, w: Widzieć, myśleć, być. Technologie mediów, red. A. Gwóźdź, Kraków 2001, s. 74-75.

30 J.-L. Marion, Ślepy w Siloe, czyli odniesienie obrazu do oryginału, dz. cyt., s. 15.

${ }^{31}$ W. Kawecki, Zobaczyć wiarę..., dz. cyt., s. 62.

32 J.-L. Marion, Ślepy w Siloe, czyli odniesienie obrazu do oryginału, dz. cyt., s. 15. 
obrazów ekranowych, dlatego „obraz powinien [...] dostosować się do tego pragnienia"33. Oglądany obraz musi stać się spełnieniem pragnienia widza, odpowiadać jego potrzebom, a w konsekwencji stać się idolem. „Każdy obraz staje się idolem albo nie jest w ogóle oglądany" - konstatuje Marion ${ }^{34}$. W ten sposób symulakrum przyczynia się do tryumfalnego powrotu idola.

\section{Ekran i sacrum}

Tę diagnozę sformułowaną $\mathrm{w}$ dużej mierze z perspektywy semiotyki obrazu elektronicznego należy teraz poddać interpretacji sub specie aeternitatis czy też sub specie fidei, co jest właściwe dla metodologii teologicznej. Zupełnie niespodziewanie próbę takiej interpretacji znalazłem w niewielkiej monografii pt. Diabeł autorstwa francuskiego historyka Georges'a Minois, który tak pisze:

[W]yzuty w zbiorowej świadomości z wszelkiej obiektywnej treści, [diabeł] może przybierać takie formy, jakie tylko komuś się zamarzą. Bardziej niż kiedykolwiek jest panem złudzenia, pozoru, kłamstwa, czyli tego, co wirtualne, co za pośrednictwem ekranu, kina, telewizji i komputerów sposobi się do kontrolowania całej ludzkości. Wszyscy wiedzą, że XXI wiek będzie wiekiem wirtualności, czyli nieistnienia, niebytu, o którym za św. Augustynem powtarzamy, iż jest jedynie innym istnieniem diabła. Czy Zły znowu puszcza do nas oko? ${ }^{35}$

Potraktujmy to stwierdzenie francuskiego historyka jako trop, a nie jako jednoznaczną teologiczną konstatację. Problem relacji wiary do tego, co wizualne, do obrazu nie jest oczywiście nowy. W historii Kościoła znamy przynajmniej dwa takie okresy, gdy ten problem był żywo dyskutowany. To późnostarożytny spór o obrazy w swym pierwszym etapie zakończony II Soborem Nicejskim w roku 787 (spór odrodził się w wieku IX) i ikonoklazm okresu Reformacji. Oba te spory koncentrowały się na dwóch pytaniach: czy obraz jest zdolny wyrazić świętość

33 J.-L. Marion, Ślepy w Siloe, czyli odniesienie obrazu do oryginału, dz. cyt., s. 16.

34 J.-L. Marion, Ślepy w Siloe, czyli odniesienie obrazu do oryginatu, dz. cyt., s. 16.

35 G. Minois, Diabet, tłum. E. Burska, Warszawa 2001, s. 158. 
bądź boskość (chodzi o status obrazu sakralnego - nie w sensie treści, ale o jego ontologię) oraz: jakiej postawy domaga się obraz od odbiorcy.

Po raz pierwszy odpowiedź na te pytania została sformułowana w kategoriach wywodzących się z filozofii platońskiej i doprowadziła do skrystalizowania się teologii ikony jako obrazu świętego. Przypisano obrazowi funkcję epifanijną, która możliwa jest dzięki relacji, jaka zachodzi między prototypem a obrazem. Tylko dlatego sobór mógł sformułować zasadę, iż „cześć oddana wizerunkowi odnosi się do prototypu” ${ }^{36}$. W ten sposób uniknięto idolatrii. Odpowiedź teologów Reformacji, dana w zupełnie innym kontekście kulturowym, zanegowała funkcję epifanijną obrazu, przypisując mu jedynie funkcję ilustracyjną, co w konsekwencji doprowadziło do przekształcenia się obrazów sakralnych na obrazy religijne. Świętość powiązano już nie z ontologią obrazu, a z jego treścią, a w konsekwencji odrzucono możliwość kultu. Była to logiczna konsekwencja, nie można bowiem oddawać czci przedstawieniu ${ }^{37}$.

Teologiczna odpowiedź na pytanie o teologiczny status obrazu elektronicznego wymyka się zarówno spod pierwszego (ikonicznego), jak i spod drugiego modelu (mimetycznego). Nie jest ona jednak jednoznaczna. Padają argumenty natury semiotycznej. Alfred Wierzbicki pisze na przykład, że

można nawet mówić o pewnej przewadze obrazu filmowego czy telewizyjnego nad obrazem malarskim, gdy chodzi o wyrażenie tajemnicy. Wiąże się to z tym, że obraz filmowy ma nie tylko semantykę, ale posiada ponadto składnię ${ }^{38}$.

Także Kawecki skłania się do waloryzacji semiotycznej obrazu telewizyjnego: „Telewizja odkrywa ponownie ze zdwojoną mocą funkcję obrazu, wizualności" ${ }^{39}$. Czy jednak przekłada się to na dodatkową teologiczną kompetencję?

W instrukcji dla fotografów kościelnych biskupi polscy przypomnieli:

36 Sobór Nicejski II, [Dekret wiary], w: Dokumenty soborów powszechnych. Tekst grecki, łaciński, polski, oprac. A. Baron, H. Pietras, tłum. A. Baron i in., t. 1, Kraków 2001, s. 339.

37 Zob. M. Bielawski, Oblicza ikony, Kraków 2006, s. 56-57.

38 A. Wierzbicki, Tajemnica telewizji, dz. cyt., s. 121-122.

39 W. Kawecki, Zobaczyć wiarę..., dz. cyt., s. 61. 
Jednakże na kliszy, jak na taśmie aparatu audiowizualnego zostają „utrwalone” jedynie drugorzędne elementy spełnionej niegdyś czynności sakramentalnej. Słowa, dźwięki, gesty „zapisane” przy pomocy tych środków technicznych pozostają martwe. Nie można bowiem utrwalić ani ludzkich przeżyć, ani nieuchwytnego dla zmysłów działania Trójosobowego Boga, stanowiącego istotę misterium - świętych czynności ${ }^{40}$.

Tej „martwoty” obrazu nie unieważnia także transmisja live. Odbiorca bowiem nie nawiązuje komunikacji z osobą przedstawioną na obrazie, ale percypuje tylko coś, co się od niego „oddziela”, a więc jedynie „ślady” jego głosu i widoku, przekształcone i transmitowane (nadawane) przez środki techniczne. „W sposób oczywisty - jak pisze Bruno Cescon - działanie o charakterze «misteryjnym» nie może zostać transmitowane w telewizji" ${ }^{41}$. Jak zauważa Zdzisław Janiec, misterium wiary

można w pewien sposób wyrazić w formie opisu słownego. Nie da się jednak ani sfotografować, ani sfilmować. Techniczne środki audiowizualne mogą zarejestrować i „utrwalić” jedynie to, co zewnętrzne, czyli słowa, gesty, czynności ${ }^{42}$.

To, co się ukazuje na ekranie telewizora, jest jedynie symulakrem zbawczej rzeczywistości. Jak zauważa Benedykt XVI, ,język obrazu [...] przedstawia rzeczywistość, ale jej samej nie uobecnia"43. Mówiąc inaczej, martwy obraz - choć przecież jakoś żywy, bo ruchomy - nie może ukazać żywej rzeczywistości.

Problem „z wiarą z widzenia” elektronicznego obrazu jest dwojaki. Po pierwsze, ekran ma idolatryczną naturę. Urzeka, pociąga, zniewala, uwodzi swym estetycznym pięknem, zatrzymując na sobie i nie przenosząc naszego wzroku ani na realność ani na prototyp. Nie jest ani

40 Wskazania Komisji Episkopatu Polski ds. Liturgii i Duszpasterstwa Liturgicznego dotyczace fotografowania i filmowania podczas celebracji liturgicznej (5.12.1994), „Liturgia Sacra” 1-2 (1995), s. 162.

${ }_{41}$ B. Cescon, Il papa dell'eccezionale, il pastore della normalità, w: Karol Wojtyła, un pontefice in diretta. Sfida e incanto nel rapporto tra Giovanni Paolo II e la TV, a cura di G. Mazza, Roma 2006, s. 219.

42 Z. Janiec, Czy liturgię można sfotografować i sfilmować?, „Sandomierski Gość Niedzielny” $2001 \mathrm{nr} 20$, s. 16.

43 Benedykt XVI, Posynodalna adhortacja apostolska "Sacramentum caritatis": o Eucharystii, źródle i szczycie życia i misji Kościoła, Kraków 2007, nr 57, s. 74-75. 
obrazem mimetycznym, ani ikonicznym. Po drugie - w konsekwencji zniewala tym, co ułudne, nieprawdziwe, a co Minois zdiagnozował jako domenę diabła. Moja diagnoza nie jest aż tak radykalna, ale trudno nie zgodzić się z faktem, że ekran jest nie-bytem.

O ile z jednej strony światło umożliwia kontemplację całości, do której człowiek zawsze aspirował, to z drugiej strony, wydaje się nie pozostawiać miejsca dla wolności, ponieważ zstępuje z nieba i dociera bezpośrednio do oka, nie wymagając, by oko odpowiedziało

- czytamy w Lumen fidei ${ }^{44}$. Jak zauważa Schönborn,

obraz zawsze niesie ze sobą jakieś zagrożenia, ponieważ nie jest jednoznaczny; nigdy nie jest „samowystarczalny”. Obraz ma dwa wymiary: ukazuje, a jednocześnie przesłania. Może objawiać, ale również wprowadzać w błąd ${ }^{45}$.

To stwierdzenie odnosi się także do medialnych wizualizacji wiary, które ujawniają się na ekranie. Światło obrazu nie pozostawia miejsca dla wolności. Tym bardziej obrazu elektronicznego. O ile jednak człowiek przednowoczesny nosił w pamięci obrazy, które ujrzał przede wszystkim w przestrzeni religijnej - tam się rodziły jego sacrae imagines, o tyle człowiek nowoczesny, poddający się libido videndi, obrazy realne miesza z ułudami ekranowymi. A co ogląda homo electronicus? Czemu „daje wiarę”? Jaka wiara rodzi się z „procesji symulakrów”? Należy chyba zgodzić się z diagnozą Minois, ponieważ złudna realność nie jest zdolna, by stać się fundamentem dla poprawnie rozumianej sakralności.

$44 \quad$ Franciszek, Encyklika Lumen fidei, dz. cyt., nr 29, s. 37.

45 Ch. Schönborn, Człowiek i Chrystus na obraz Boga, dz. cyt., s. 95. 


\section{Summary}

\section{Fides ex visu. 0 medialnych wizualizacjach wiary}

Artykuł podejmuje temat teologicznego statusu obrazu wjego wersji elektronicznej, czyli jako ekranu. W chrześcijaństwie kwestia teologii obrazu podejmowana jest od czasów sporów ikonoklastycznych na Wschodzie (VIII-IX w.). Teologia zachodnia od X wieku, a potem na skutek Reformacji, krytycznie podchodziła do epifanijnej funkcji obrazu, która dla chrześcijaństwa wschodniego jest oczywista. Ten teologiczny dystans wobec spełniania funkcji epifanijnej dominuje w teologicznej interpretacji obrazu elektronicznego. Przyjmuje się, że obraz elektroniczny (ekran) nie jest zdolny, by transmitować misterium. Kategoria „symulakrum”, którą stosuje się w opisie obrazu elektronicznego, wskazuje na zerwanie z ikonicznym bądź mimetycznym odwzorowaniem rzeczywistości. Symulakrum imituje rzeczywistość przedstawioną, dlatego nie jest w stanie jej objawiać.

Słowa kluczowe: obraz, symulakrum, hiperrealność

\section{Fides ex visu. On Visualisations of Faith in Media}

The article discusses the theological status of an image in its electronic version, i.e. as a screen. In Christianity, the theology of an image has been an issue since the iconoclastic disputes in the East (8th and 9th century). From the 10th century, and then as a result of Reformation, the Western theology approached the epiphanic function of the image, which is evident in Eastern Christianity, with criticism. This theological reserve towards an epiphanic function of an electronic image (screen) dominates the theological interpretation of it. An electronic image is assumed to be incapable of transmitting mystery. The category of "simulacrum", used in the description of the electronic image, indicates a breakup with the iconic or mimetic representation of reality. Simulacrum only imitates the presented reality, so it is unable to perform a revelatory function.

Keywords: image, simulacrum, hyperrealism

(tłum. A. Piskozub-Piwosz) 


\section{Bibliografia}

Baudrillard J., Porządek symulakrów, w: Widzieć, myśleć, być. Technologie mediów, red. A. Gwóźdź, Kraków 2001, s. 63-78.

Belting H., Obraz i kult. Historia obrazu przed epoka sztuki, tłum. T. Zatorski, Gdańsk 2004.

Benedykt XVI, Posynodalna adhortacja apostolska „Sacramentum caritatis”: o Eucharystii, źródle i szczycie życia i misji Kościoła, Kraków 2007.

Bielawski M., Oblicza ikony, Kraków 2006.

Cescon B., Il papa dell'eccezionale, il pastore della normalità, w: Karol Wojtyła, un pontefice in diretta. Sfida e incanto nel rapporto tra Giovanni Paolo II e la TV, a cura di G. Mazza, Roma 2006, s. 213-220.

Franciszek, Encyklika Lumen fidei, Wrocław [2013].

Freedberg D., Potęga wizerunków. Studia z historii i teorii oddziaływania, tłum. E. Klekot, Kraków 2005.

Gut A., O relacji między myśla a językiem: studium krytyczne stanowisk utożsamiających myśl zjęzykiem, Lublin 2009.

Jan Damasceński św., Wykład wiary prawdziwej, przeł. B. Wojkowski, Warszawa 1969.

Janiec Z., Czy liturgię można sfotografowaći sfilmować?, „Sandomierski Gość Niedzielny" $2001 \mathrm{nr} 20$, s. 16.

Kawecki W., Zobaczyć wiarę. Studium obrazu postrzeganego jako komunikacja wiary z perspektywy teologii kultury i teologii mediów, Kraków 2013.

Loska K., Dziedzictwo McLuhana - między nowoczesnościa a ponowoczesnościa, Kraków 2001.

Manovich L., Ku archeologii ekranu komputerowego, w: Widzieć, myśleć, być. Technologie mediów, red. A. Gwóźdź, Kraków 2001, s. 167-190.

Marion J.-L., Ślepy w Siloe, czyli odniesienie obrazu do oryginału, „Communio” (wyd. pol.) 2 (1990), s. 12-29.

Miczka T., o zmianie zachowań komunikacyjnych. Konsumenci w nowych sytuacjach audiowizualnych, Katowice 2002.

Minois G., Diabet, tłum. E. Burska, Warszawa 2001.

Mitchell W. J. T., Czego chca obrazy. Pragnienia przedstawień, życie i miłości obrazów, tłum. Ł. Zaremba, Warszawa 2013.

Morgan D., Visual Piety. A History and Theory of Popular Religious Images, Berkeley-Los Angeles-London 1998.

Niparko R., Amalary z Metzu, w: Encyklopedia katolicka, t. 1, red. E. Gigilewicz, Lublin 1995, kol. 399.

Ogonowska A., Symulakrum, „Nowa Polszczyzna” 1 (2006), s. 29-32.

Porczak A., Ekran - pole transakcji, w: Wiek ekranów. Przestrzenie kultury widzenia, red. A. Gwóźdź, P. Zawojski, Kraków 2002, s. 45-52.

Schönborn Ch., Człowiek i Chrystus na obraz Boga, tłum. W. Szymona, Poznań 2008. 
Sobór Nicejski II, [Dekret wiary], w: Dokumenty soborów powszechnych. Tekst grecki, łaciński, polski, t. 1, oprac. A. Baron, H. Pietras, tłum. A. Baron i in., Kraków 2001, s. 330-341.

Sontag S., Widok cudzego cierpienia, Kraków 2010.

Weber S., Telewizja: odbiornik i ekran, w: Widzieć, myśleć, być. Technologie mediów, red. A. Gwóźdź, Kraków 2001, s. 381-398.

Wierzbicki A., Tajemnica telewizji, w: O Panu Bogu w telewizji, red. L. Dyczewski, Częstochowa 1996, s. 107-124.

Winnicka-Gburek J., Krytyka - etyka - sacrum. W kierunku aksjologicznej krytyki artystycznej, Gdańsk 2015.

Wskazania Komisji Episkopatu Polski ds. Liturgii i Duszpasterstwa Liturgicznego dotyczace fotografowania i filmowania podczas celebracji liturgicznej (5.12.1994), „Liturgia Sacra” 1-2 (1995), s. 161-164. 